\title{
Evaluation of brake parameters in copper discs of various thicknesses and speeds using Neodymium - Iron - Boron Magnets
}

\author{
G. L. Anantha Krishna ${ }^{1}$ and K. M. Sathish Kumar ${ }^{*}$ \\ ${ }^{1}$ Department of Mechanical Engineering, BMS Institute of Technology \& Management, Bengaluru, \\ 560064, India
}

\begin{abstract}
Neodymium - Iron - Boron $(\mathrm{NdFeB})$ permanent magnets of $12.5 \mathrm{~mm}$ thickness and $50 \mathrm{~mm}$ diameter are chosen for analyses because of their higher remanence and coercivity. Experimental analyses were carried out with Copper discs of thickness $4 \mathrm{~mm}, 6 \mathrm{~mm}$ and $8 \mathrm{~mm}$ at $2000 \mathrm{rpm}$, $3000 \mathrm{rpm}, 4000 \mathrm{rpm}$ and $5000 \mathrm{rpm}$. Experiments were conducted with three different positions of magnets such as 2 coaxial magnets, single magnet and single magnet with sudden application conditions. The brake parameters recorded are $\%$ speed reduction, deceleration and time taken. In 2 coaxial magnets condition, brake parameters are better in $6 \mathrm{~mm}$ thick disc. In single magnet condition, the brake parameters in $6 \mathrm{~mm}$ thick disc are found to be more consistent than $4 \mathrm{~mm}$ and $8 \mathrm{~mm}$ thick discs. In single magnet with sudden application condition, in $4 \mathrm{~mm}$ thick disc, the brake parameters are found better. During analysis, very high repulsion was experienced by magnet with $8 \mathrm{~mm}$ thick Copper disc at all the above mentioned speeds in single magnet with sudden application condition. For high speed train applications, single magnet condition with $6 \mathrm{~mm}$ thick disc may be suitable. For high speed automotive applications, single magnet with sudden application condition with $4 \mathrm{~mm}$ thick disc may be suitable.
\end{abstract}

\section{Introduction}

Conventional friction brakes have numerous problems such as brake squealing noise [1 10], thermal cracking and thermo mechanical failures [11 - 15], fade and recovery behavior of friction material [16 - 17], effects due to formulation of ingredients of materials of brake lining [18 - 23], brake judder [24 - 25], brake grabbing, disc distortion etc.

The eddy current principle states that a non - stationary magnetic field induces swirl like electric currents in a conductive body subjected to its influence. These eddy currents occur either when a moving conductive body crosses a magnetic field or by imposing a varying magnetic field upon a stationary conductor.

The eddy currents generate a magnetic field whose flux is opposite to the applied one, in an attempt to reduce the net magnetic flux to zero. This magnetic interaction generates the force necessary to cause a deceleration of the conductor body. This idea can be

\footnotetext{
*Corresponding author: sathishmech@bmsit.in
} 
implemented in high speed trains and high speed automotive application. During braking, the metal wheels are exposed to a magnetic field from an electromagnet or permanent magnets, generating eddy currents in the wheels. The magnetic interaction between the applied field and the eddy currents acts to slow the wheels down. The faster the wheels are spinning, the stronger the effect, meaning that as the train slows the braking force is reduced, producing a smooth stopping motion. The advantage associated with this lies in the absence of moving parts, being contactless system there is no wear of brake pads. The drag force is given by $\mathrm{F}_{\mathrm{d}}=\alpha \sigma \delta \mathrm{B}^{2} \mathrm{AV}$ [26] where $\mathrm{F}_{\mathrm{d}}$ is drag force, $\alpha$ is a constant, $\sigma$ is conductivity of conductor, $\mathrm{B}$ is flux density, $\mathrm{A}$ is area created by permanent magnet, $\mathrm{V}$ is velocity of conducting plate. If a disc made of conducting material associated with the shaft is considered, it is a moving conductor. The necessary magnetic field can be obtained by means of an electromagnet or permanent magnet. Braking torque is directly proportional to the speed of the moving conductor.

A permanent magnet is an object made from a material that is magnetized and creates its own persistent magnetic field. An electromagnet is made from a coil wire that acts as a magnet when an electric current passes through it but stops being a magnet when the current stops.

Rare earth magnets offer high values of flux density at very high values of magnetizing force. Consequently, very short magnet lengths are needed and hence volume of magnet will be small. Various rare earth magnets in use are Neodymium - Iron - Boron (NdFeB) magnets [27], Samarium-cobalt magnet, Alnico magnets. A neodymium magnet is the most widely used type of rare earth magnet. It is a permanent magnet made from an alloy of neodymium, iron and boron $(\mathrm{NdFeB})$. $\mathrm{NdFeB}$ magnets have higher remanence, much higher coercivity and energy product.

Flux density is a measure of how concentrated the magnetic field is. Permeability is a measure of how easily a magnetic field can be set up in a material. When the induced moment is opposite to the applied magnetic field, such materials are called diamagnetic materials, e.g. copper. In diamagnetic substances, the flux grows slightly more slowly with the field than it does in the vacuum.

The disadvantage of electromagnetic brakes is its compatibility with signaling and train control systems. Electromagnetic forces are generated when the eddy current brake is activated. These forces could result in interference or potentially even irreparable damage to the signaling systems [28]. Also, electromagnetic braking system is very expensive.

As the drag force is dependent on thickness of conductor, conductivity of conductor, velocity of conductor $\mathrm{NdFeB}$ magnets having higher energy product, remanence and coercivity, author tried to analyses experimentally the effect of thickness, speed on brake parameters such as \% speed reduction, deceleration and time taken using Copper as conducting material and $\mathrm{NdFeB}$ permanent magnets.

\section{Methodology}

To carry out the experiments, a special purpose test rig was developed and fabricated. The test rig is as shown in Fig. 1. The base is made of Aluminum on which a DC motor of $10,000 \mathrm{rpm}$ is mounted. Stainless steel shaft is coupled to motor on which discs of thickness $4 \mathrm{~mm}, 6 \mathrm{~mm}$ and $8 \mathrm{~mm}$ made of Copper are mounted. The diameter of the discs chosen is $200 \mathrm{~mm}$. The speeds at which experiments were conducted are $2000 \mathrm{rpm}, 3000$ $\mathrm{rpm}, 4000 \mathrm{rpm}$ and $5000 \mathrm{rpm}$ to simulate speeds of $75 \mathrm{~km} / \mathrm{hr}, 113 \mathrm{~km} / \mathrm{hr}, 150.8 \mathrm{~km} / \mathrm{hr}$ and $188.5 \mathrm{~km} / \mathrm{hr}$ respectively. The speed of discs is controlled using dimmerstat. The magnets are mounted on threaded shafts made of gunmetal. Permanent magnets are moved towards and away from rotating disc using stepper motors. The magnets move towards rotating disc at a velocity of $4 \mathrm{~mm} / \mathrm{second}$. The values of Magnetic flux density of magnets and speed of 
discs are acquired through Hall Effect sensor and optical speed sensor respectively which are mounted close to the disc. The Arduino Uno microcontroller board based on the ATmega328 is used for data acquisition and processing. Ultrasonic ranging module HC SR04 provides $20 \mathrm{~mm}-4000 \mathrm{~mm}$ non-contact measurement function to measure gap between disc and magnet is used.

The NdFeB magnets of $12.5 \mathrm{~mm}$ thickness and $50 \mathrm{~mm}$ diameter are chosen for investigations. Various parameters such as disc speed, magnetic flux density, gap between disc and magnets, time taken for speed reduction and deceleration are acquired through data acquisition system with a special software developed using $\mathrm{C} \#$.

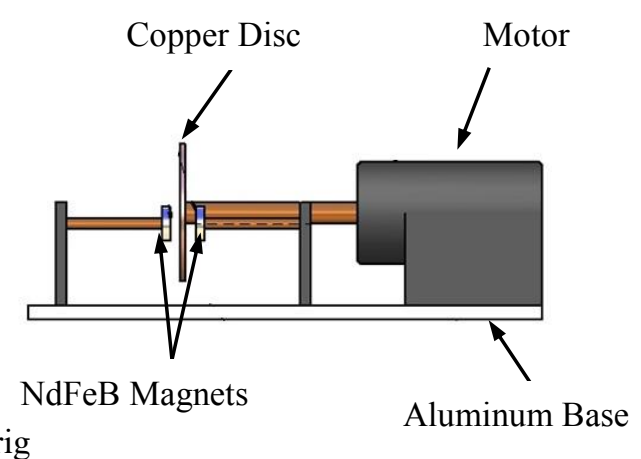

Fig. 1. Schematic of test rig

Experiments were conducted with different positions of magnets and movement of magnets towards rotating disc. The experiments were conducted with gradual movement of magnets towards disc and sudden movement towards disc. The gradual movement of magnets is to simulate braking sequence in high speed train applications whereas sudden application is to simulate braking sequence in high speed automotive application. The different positions of magnets with which experiments were carried out are as shown in Fig. 2.

- 2 coaxial magnets on either side of rotating disc and move at a velocity of 4 $\mathrm{mm} / \mathrm{second}$ towards rotating disc.

- Single magnet on one side of rotating disc and moves with a velocity of 4 $\mathrm{mm} / \mathrm{second}$ towards rotating disc.

- Single magnet on one side of rotating disc and moves towards rotating disc suddenly to simulate the actual brake application condition.

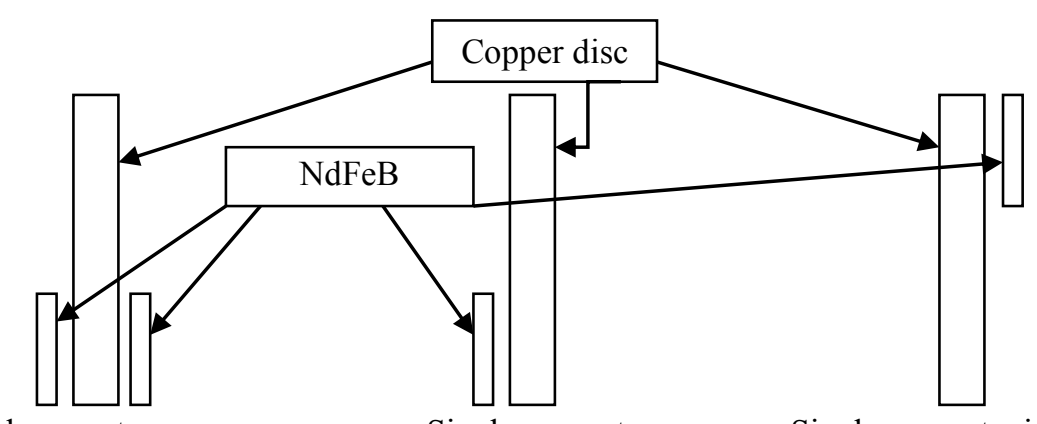

2 coaxial magnets

Single magnet

Single magnet with sudden

Fig. 2. Schematic of different positions of magnets application 
The electrical conductivity, permeability and susceptibility properties of Copper are $5.96 \times$ $10^{7}$ Siemens/m, $1.256629 \times 10^{-6}$ Henry/m and $-9.2 \times 10^{-6}$ respectively. As Copper is diamagnetic material, induced magnetization is slightly slow.

\section{Results and discussions}

In the present work the experiments were carried out with permanent magnets made of Neodymium - Iron - Boron (NdFeB) magnets of $12.5 \mathrm{~mm}$ thickness and $50 \mathrm{~mm}$ diameter. All the discs are of $200 \mathrm{~mm}$ diameter. The speeds at which experiments were conducted are $2000 \mathrm{rpm}, 3000 \mathrm{rpm}, 4000 \mathrm{rpm}$ and $5000 \mathrm{rpm}$ to simulate speeds of $75 \mathrm{~km} / \mathrm{hr}, 113 \mathrm{~km} / \mathrm{hr}$, $150.8 \mathrm{~km} / \mathrm{hr}$ and $188.5 \mathrm{~km} / \mathrm{hr}$ respectively. Repulsion was experienced by magnets when brought closer than $5 \mathrm{~mm}$ from the rotating disc. Hence, the gap between disc and magnet was maintained at $5 \mathrm{~mm}$ for all the conditions of positions of magnets. From experimental investigations it was observed that the induced magnetization begins when distance between magnets and rotating disc is $35 \mathrm{~mm}$. Induced magnetization increases as the distance between magnets and disc decreases.

Experiments were carried out to study the influence of various parameters such as conductivity, permeability, susceptibility of Copper, speed of Copper disc and thickness of Copper discs on braking parameters such as \% speed reduction, deceleration and time taken for speed reduction. The time taken is estimated when the distance between magnets and rotating disc is $5 \mathrm{~mm}$. Deceleration considered is the maximum value recorded during experimentation. Investigations were carried out with Copper discs of $4 \mathrm{~mm}, 6 \mathrm{~mm}$ and 8 $\mathrm{mm}$ thickness at $2000 \mathrm{rpm}, 3000 \mathrm{rpm}, 4000 \mathrm{rpm}$ and $5000 \mathrm{rpm}$.

\subsection{Two coaxial magnets condition}

Experiments under this condition was carried out to understand the influence of two magnets on induced magnetization when positioned on the same axis but on either side of rotating disc. Fig. 3, Fig. 4 and Fig. 5 indicates comparisons of \% speed reduction, time taken for speed reduction and deceleration values for various thicknesses of Copper discs at $2000 \mathrm{rpm}, 3000 \mathrm{rpm}, 4000 \mathrm{rpm}$ and $5000 \mathrm{rpm}$ respectively in 2 coaxial magnets condition.

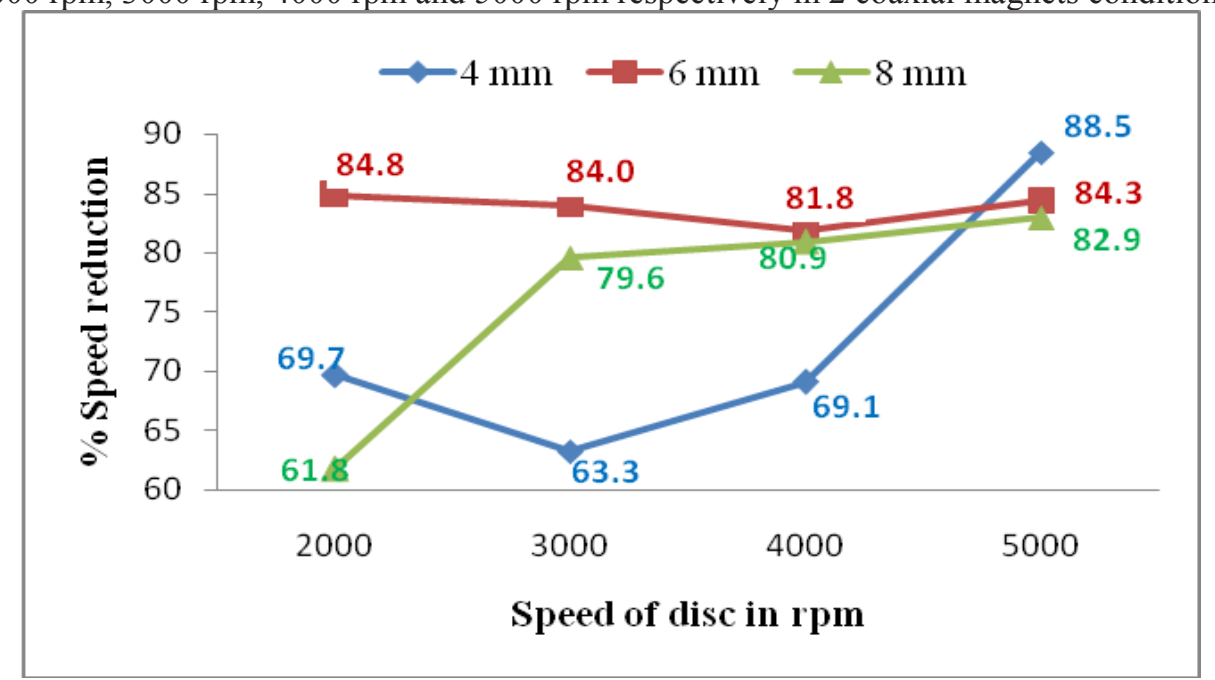

Fig. 3. Comparison of $\%$ speed reduction of Copper discs in 2 coaxial magnets condition 


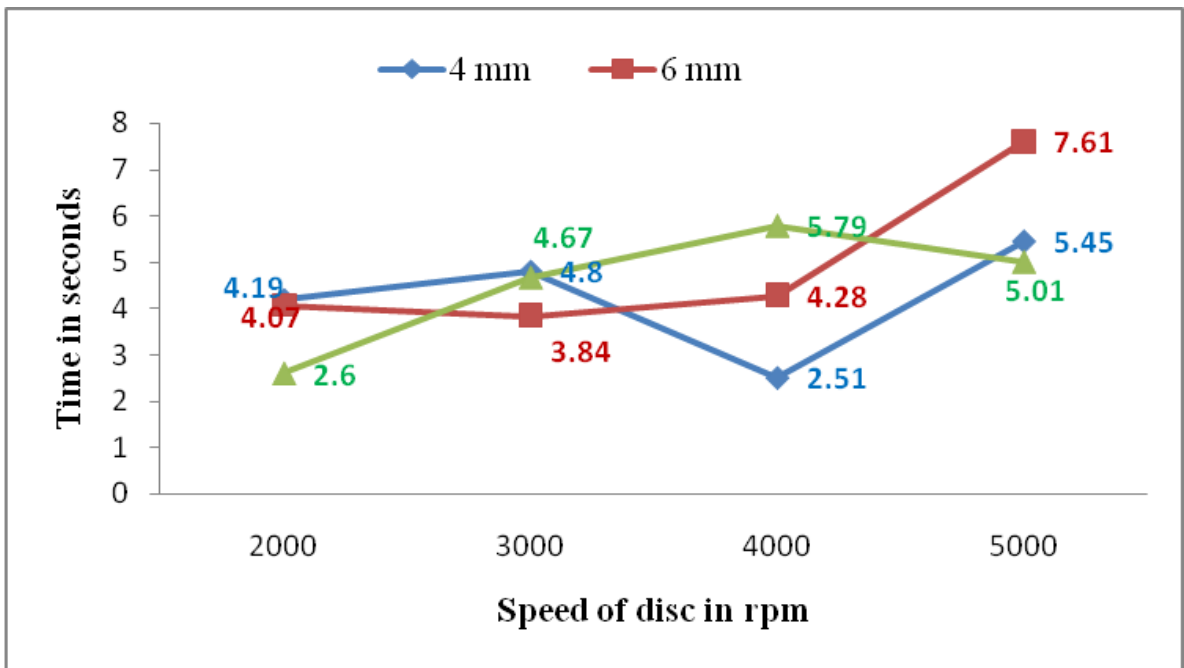

Fig. 4. Comparison of time of Copper discs in 2 coaxial magnets condition

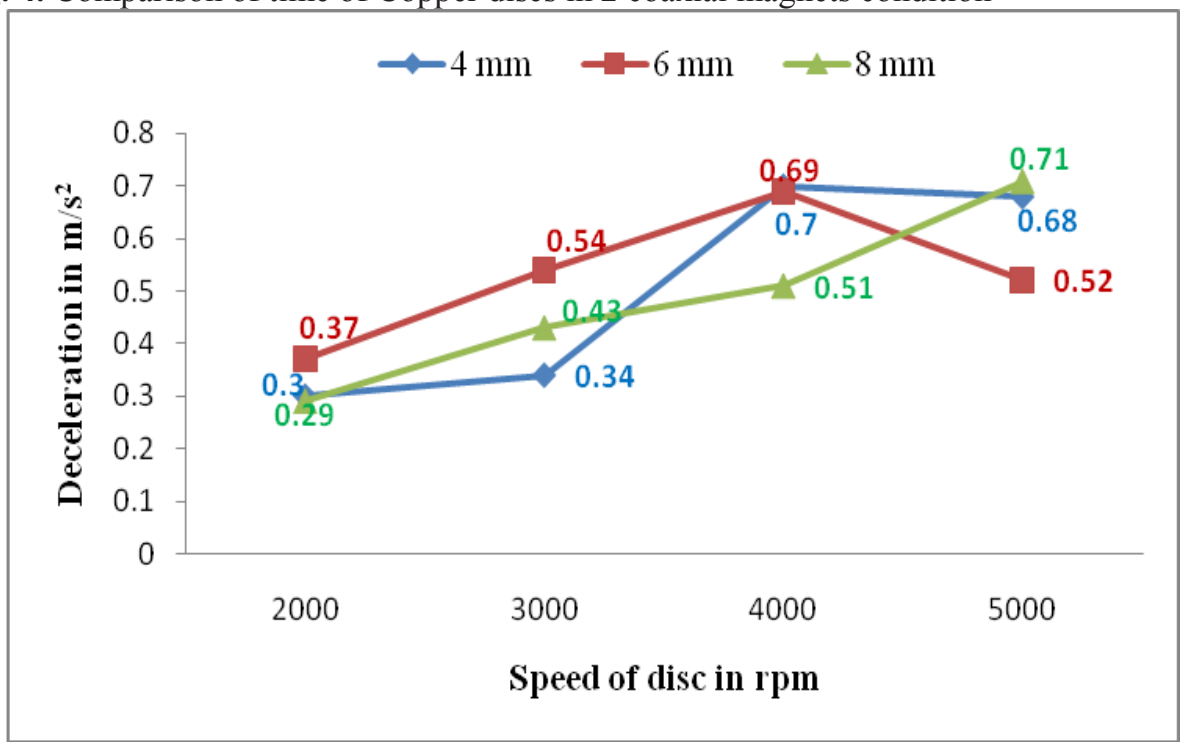

Fig. 5. Comparison of deceleration of Copper discs in 2 coaxial magnets condition

Referring to Fig. 3, it can be observed that, in $6 \mathrm{~mm}$ thick disc, \% speed reductions are $84.8 \%, 84 \%, 81.8 \%$ and $84.3 \%$ at $2000 \mathrm{rpm}, 3000 \mathrm{rpm}, 4000 \mathrm{rpm}$ and $5000 \mathrm{rpm}$ respectively. These \% speed reductions are higher compared to that of $4 \mathrm{~mm}$ and $8 \mathrm{~mm}$ thick discs. Also, the \% speed reductions are uniform at all the above said speeds. It can be observed that \% speed reduction is more in $6 \mathrm{~mm}$ thick disc than that in $4 \mathrm{~mm}$ thick disc. This is due to the fact that the drag force is directly proportional to the thickness of conductor. However, in $8 \mathrm{~mm}$ thick disc there is a decrease in \% speed reduction. This may due to skin effect wherein in very fast changing fields, the magnetic field does not penetrate completely into the interior of the material.

Time taken was estimated when the distance between magnets and disc was $5 \mathrm{~mm}$ as it was observed that induced magnetization increased as the distance between magnets and disc decreased. Referring to Fig. 4, it can be observed that in $6 \mathrm{~mm}$ thick disc, the time taken for speed reductions are $4.07 \mathrm{~s}, 3.84 \mathrm{~s}, 4.28 \mathrm{~s}$ and $7.61 \mathrm{~s}$ at $2000 \mathrm{rpm}, 3000 \mathrm{rpm}, 4000$ 
rpm and $5000 \mathrm{rpm}$ respectively. The time taken is less at $2000 \mathrm{rpm}, 3000 \mathrm{rpm}, 4000 \mathrm{rpm}$ compared to the time taken in $4 \mathrm{~mm}$ and $8 \mathrm{~mm}$ thick discs. However, at $5000 \mathrm{rpm}$, the time taken is high at $7.61 \mathrm{~s}$. This may be due to slow growth of flux in the disc.

Deceleration considered is the maximum value recorded during the experimentation. Referring to Fig. 5, it can be observed that the deceleration in $6 \mathrm{~mm}$ thick disc is higher compared to the decelerations of $4 \mathrm{~mm}$ and $8 \mathrm{~mm}$ thick discs. The decelerations recorded for $6 \mathrm{~mm}$ thick disc are $0.37 \mathrm{~ms}^{-2}, 0.54 \mathrm{~ms}^{-2}, 0.69 \mathrm{~ms}^{-2}$ and $0.52 \mathrm{~ms}^{-2}$ at $2000 \mathrm{rpm}, 3000$ $\mathrm{rpm}, 4000 \mathrm{rpm}$ and $5000 \mathrm{rpm}$ respectively. It can be observed that at $5000 \mathrm{rpm}$, the time taken is more compared to $4 \mathrm{~mm}$ and $8 \mathrm{~mm}$ thick discs. This is due to slow flux growth and more time taken and hence lesser deceleration.

It may be observed that the brake parameters such as \% speed reduction, time taken to achieve speed reduction and deceleration of $6 \mathrm{~mm}$ thick disc were found to be better compared with those of $4 \mathrm{~mm}$ and $8 \mathrm{~mm}$ thick discs. It can be observed that the deceleration is tolerable and speed reduction is gradual.

\subsection{Single magnet condition}

In this condition of experimentation, only one magnet is moved towards rotating disc at 4 $\mathrm{mm} / \mathrm{sec}$ velocity. This condition of position of magnet was chosen to understand the behavior on induced magnetization. Fig. 6, Fig. 7 and Fig. 8 indicates comparisons of \% speed reduction, time taken for speed reduction and deceleration values for various thicknesses of Copper discs at $2000 \mathrm{rpm}, 3000 \mathrm{rpm}, 4000 \mathrm{rpm}$ and $5000 \mathrm{rpm}$ respectively in single magnet condition.

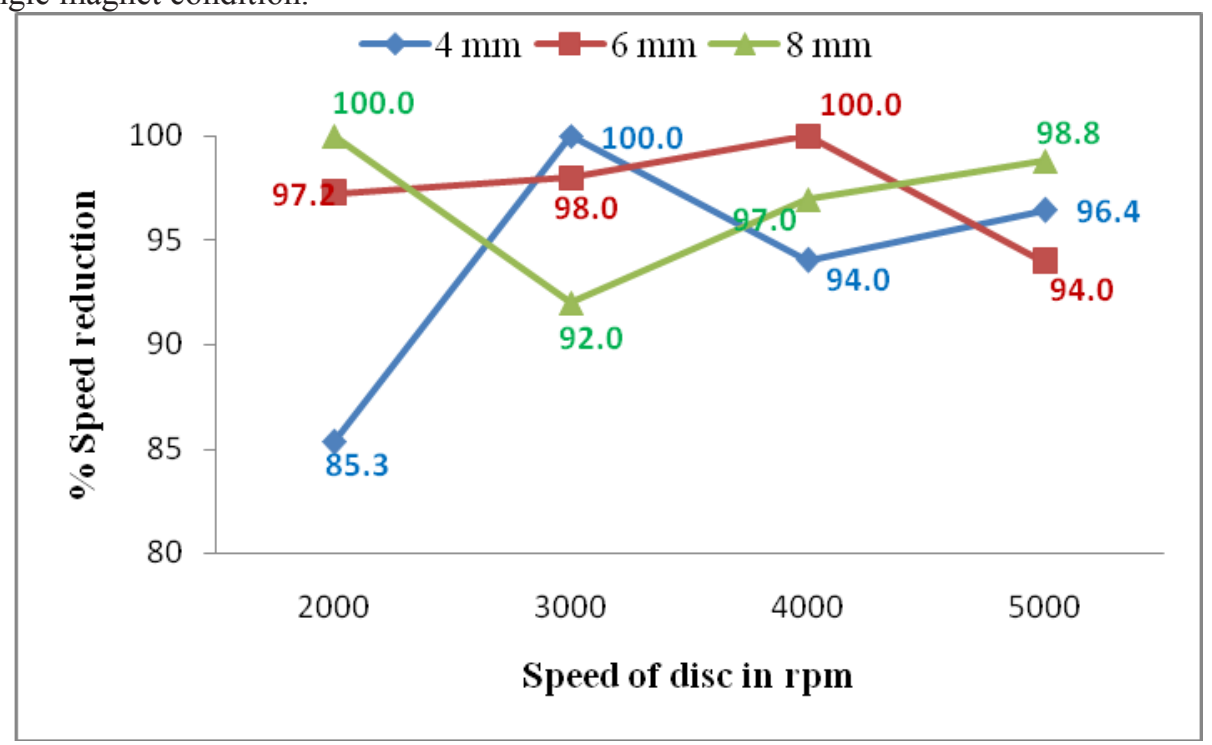

Fig. 6. Comparison of $\%$ speed reduction of Copper discs in single magnet condition 


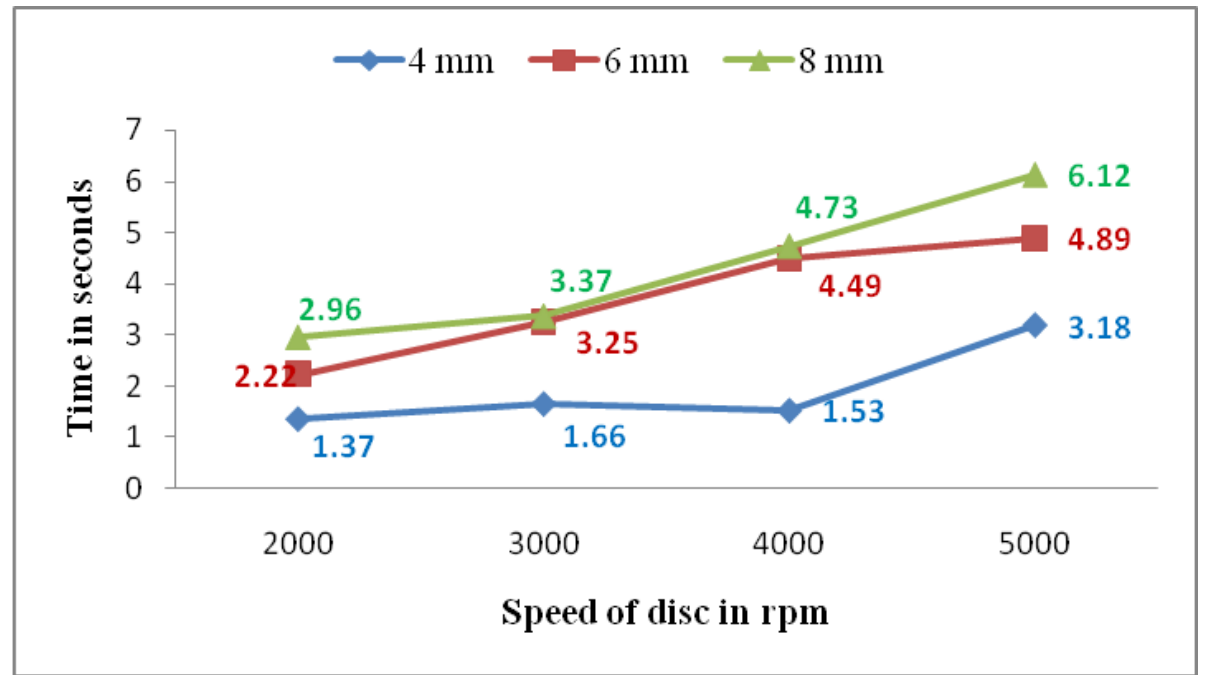

Fig. 7. Comparison of time of Copper discs in single magnet condition

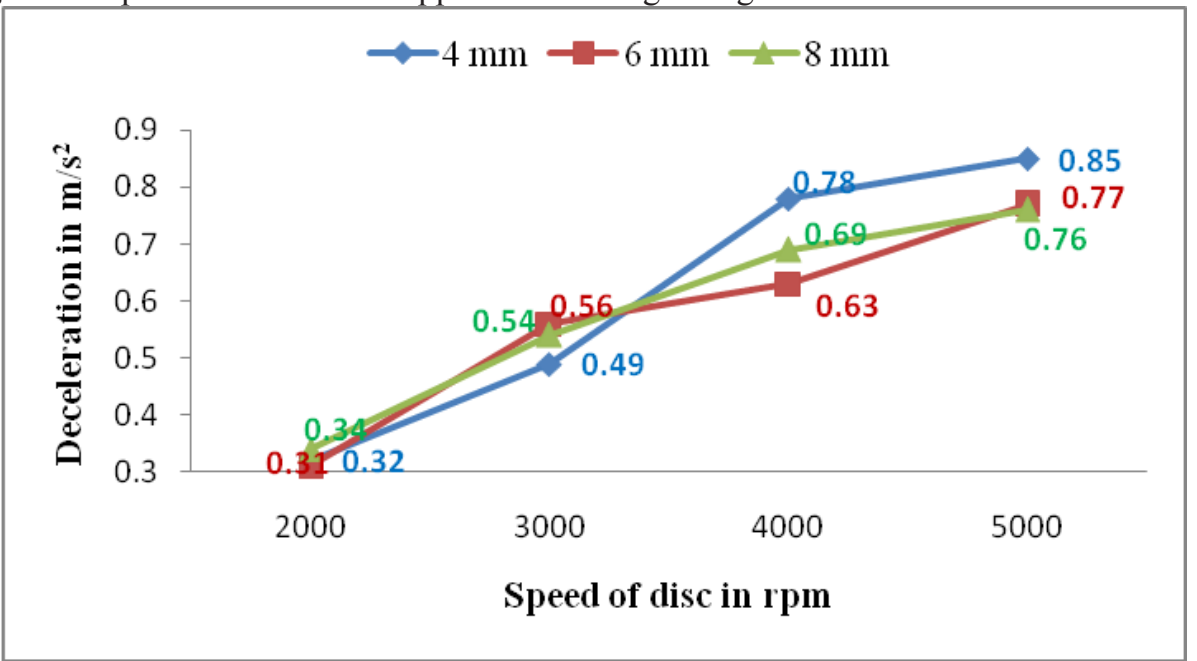

Fig. 8. Comparison of deceleration of Copper discs in single magnet condition

Referring to Fig. 6, it can be observed that in $6 \mathrm{~mm}$ thick disc, \% speed reductions are $97.2 \%, 98 \%, 100 \%$ and $94.0 \%$ at $2000 \mathrm{rpm}, 3000 \mathrm{rpm}, 4000 \mathrm{rpm}$ and $5000 \mathrm{rpm}$ respectively. Even though the \% speed reduction in $4 \mathrm{~mm}$ thick disc and $8 \mathrm{~mm}$ thick disc are comparable to that of $6 \mathrm{~mm}$ thick disc, the \% speed reduction is higher and more uniform in $6 \mathrm{~mm}$ thick disc. This may be due to skin effect in $4 \mathrm{~mm}$ thick disc and magnetization in $8 \mathrm{~mm}$ thick disc. Magnetization $\mathrm{M}=\frac{\mathrm{m}}{V}$, as volume increases, magnetization decreases.

Referring to Fig. 7, it can be observed that in $4 \mathrm{~mm}$ thick disc, the time taken for speed reductions are $1.37 \mathrm{~s}, 1.66 \mathrm{~s}, 1.53 \mathrm{~s}$ and $3.184 \mathrm{~s}$ at $2000 \mathrm{rpm}, 3000 \mathrm{rpm}, 4000 \mathrm{rpm}$ and 5000 rpm respectively. The time taken is less compared to the time taken in $6 \mathrm{~mm}$ and $8 \mathrm{~mm}$ thick discs. This is due to the reason that speed reduction is faster in $4 \mathrm{~mm}$ thick disc than that in $6 \mathrm{~mm}$ and $8 \mathrm{~mm}$ thick discs at $2000 \mathrm{rpm}, 3000 \mathrm{rpm}, 4000 \mathrm{rpm}$ and $5000 \mathrm{rpm}$.

Referring to Fig. 8, it can be observed that the deceleration in $4 \mathrm{~mm}$ thick disc is found to be comparable with the decelerations of $6 \mathrm{~mm}$ and $8 \mathrm{~mm}$ thick discs. The decelerations 
recorded for $4 \mathrm{~mm}$ thick disc are $0.32 \mathrm{~ms}^{-2}, 0.49 \mathrm{~ms}^{-2}, 0.78 \mathrm{~ms}^{-2}$ and $0.85 \mathrm{~ms}^{-2}$ at $2000 \mathrm{rpm}$, $3000 \mathrm{rpm}, 4000 \mathrm{rpm}$ and $5000 \mathrm{rpm}$ respectively.

From the point of view of higher speed reduction achieved, less time taken and higher deceleration, $4 \mathrm{~mm}$ thick Copper disc can be a better option in single magnet condition.

\subsection{Comparison between two coaxial magnets condition and single magnet condition}

In 2 coaxial magnets $\%$ speed reduction is less and time for speed reduction is more. This may be due to nullifying effect of magnetic flux when two magnets come closer to disc. When like poles are placed near each other, their magnetic fields cancel each other, and there is a neutral point where the combined field strength is zero. Also, there is repulsion between magnets which may be causing the reduction in induced magnetization. However, speed reduction is more gradual compared to single magnet condition.

In single magnet condition, as the Copper is diamagnetic material, flux growth is slow. Even though the flux growth is slow which is evident from higher time taken for speed reduction, $\%$ of speed reduction is more in single magnet condition compared to 2 coaxial magnets condition. It may be observed that brake parameters such as \% speed reduction, time taken for speed reduction and deceleration are better in single magnet condition.

From the point of view of $\%$ speed reduction, comparable time taken and moderate deceleration, both $4 \mathrm{~mm}$ thick and $6 \mathrm{~mm}$ thick Copper discs in single magnet condition can be used for high speed train applications. Since the mechanism requirements in single magnet condition are less, single magnet condition will be more economical. Also, because $4 \mathrm{~mm}$ thick disc is lesser in weight, more economical and less space consuming compared with $6 \mathrm{~mm}$ and $8 \mathrm{~mm}$ discs, $4 \mathrm{~mm}$ thick disc is economical and advantageous.

\subsection{Single magnet with sudden application condition}

In this condition of experimentation, only one magnet is moved towards rotating disc suddenly. This is to simulate actual braking condition in automobiles. This condition of position of magnet was chosen to understand the behavior on induced magnetization when magnet is brought closer to the rotating disc at a rapid pace. Fig. 9, Fig. 10 and Fig. 11 indicates comparisons of $\%$ speed reduction, time taken for speed reduction and deceleration values for various thicknesses of Copper discs at $2000 \mathrm{rpm}, 3000 \mathrm{rpm}, 4000$ rpm and $5000 \mathrm{rpm}$ respectively in single magnet with sudden application condition.

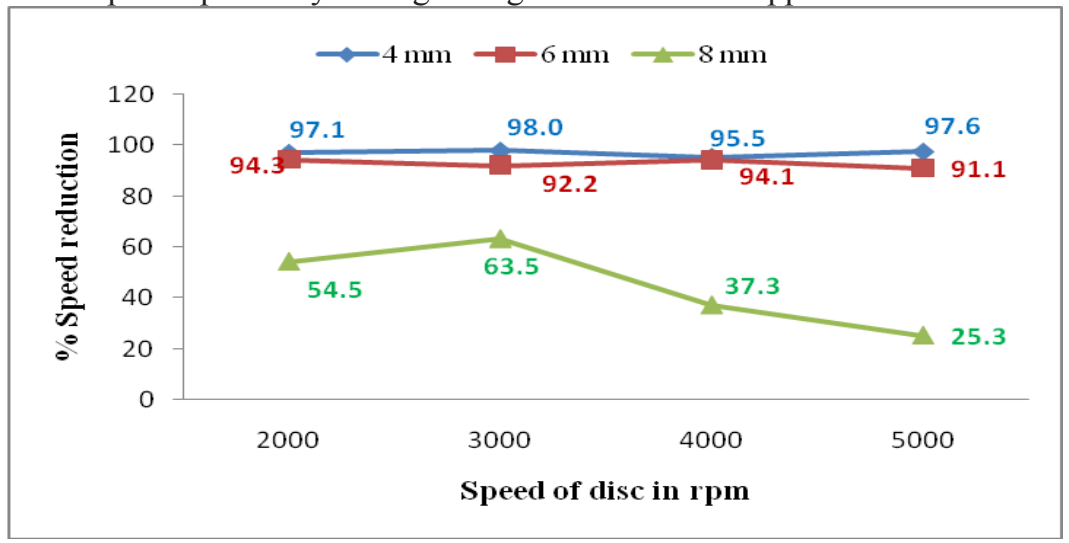

Fig. 9. Comparison of \% speed reduction of Copper discs in single magnet with sudden application condition 


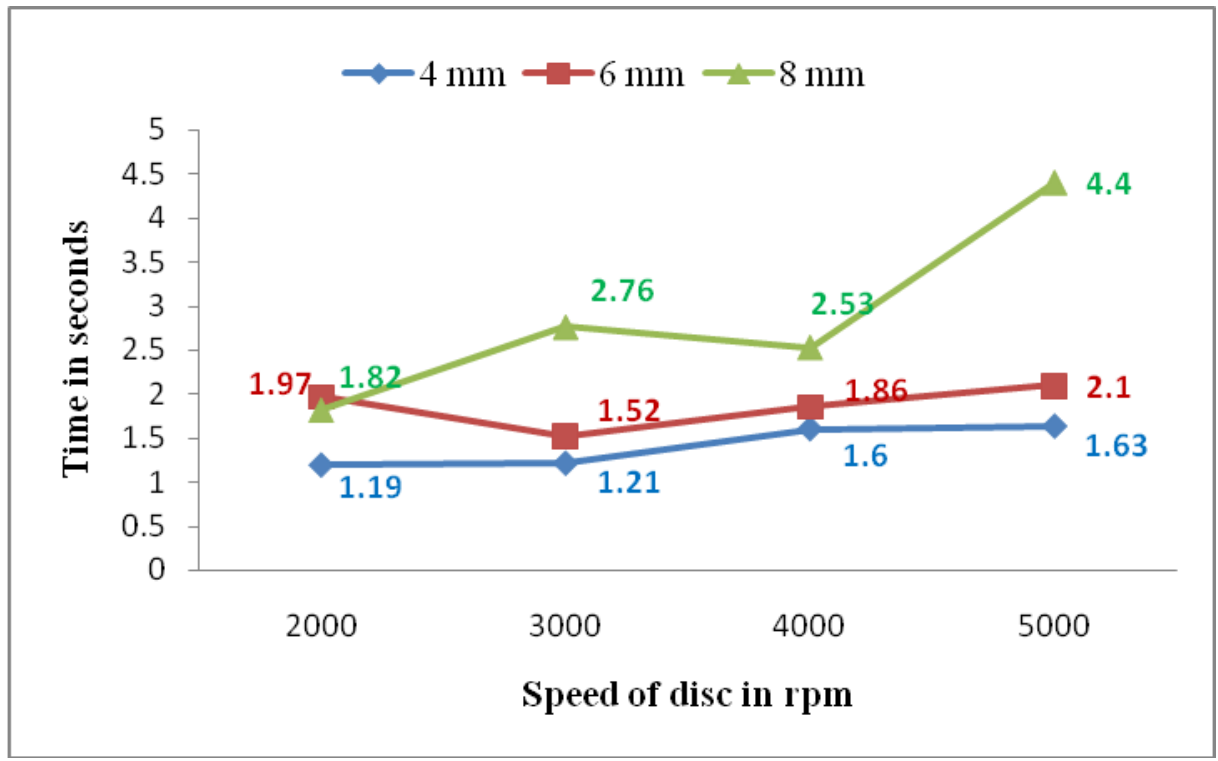

Fig. 10. Comparison of time of Copper discs in single magnet with sudden application condition

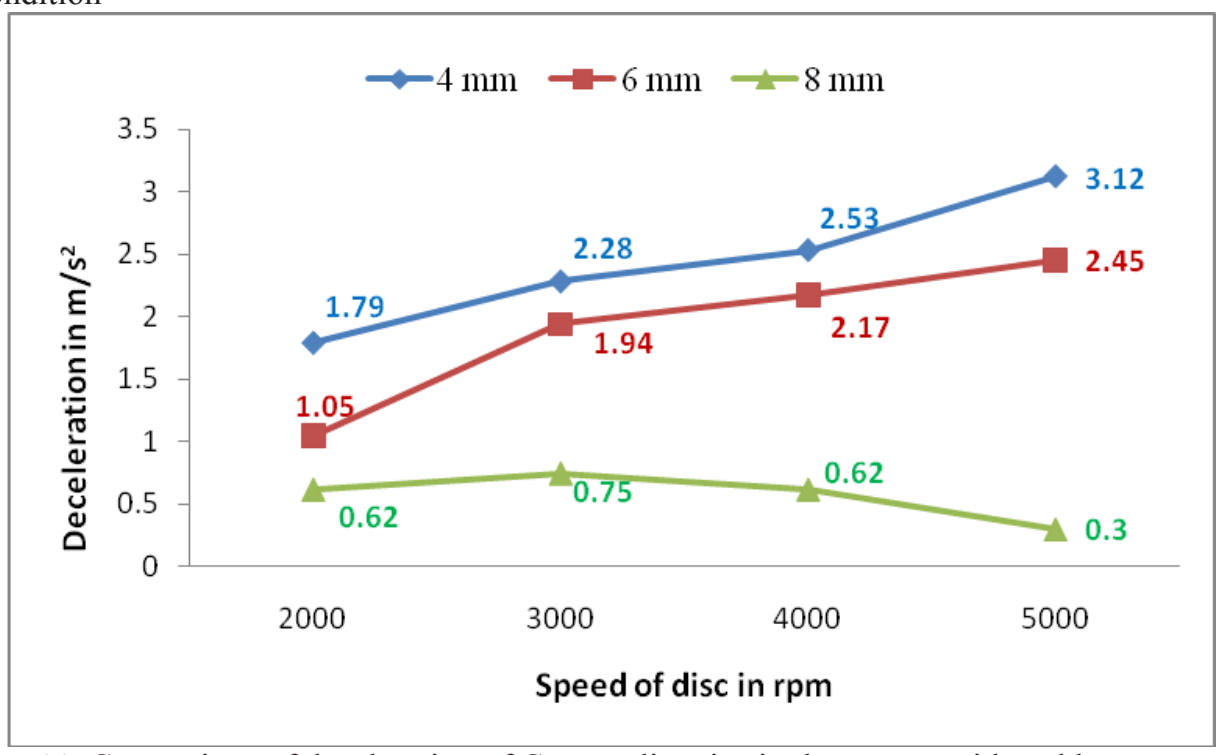

Fig. 11. Comparison of deceleration of Copper discs in single magnet with sudden application condition

Referring to Fig. 9, it can be observed that in $4 \mathrm{~mm}$ thick disc, \% speed reductions are $97.1 \%, 98 \%, 95.5 \%$ and $97.6 \%$ at $2000 \mathrm{rpm}, 3000 \mathrm{rpm}, 4000 \mathrm{rpm}$ and $5000 \mathrm{rpm}$ respectively. These $\%$ speed reductions are higher and more uniform for all speeds compared to that of $6 \mathrm{~mm}$ and $8 \mathrm{~mm}$ thick discs. It was observed that a very high repulsion was experienced with $8 \mathrm{~mm}$ thick disc at all the aforesaid speeds. This may be due to high magnetic induction which repelled the original magnetic field. Also, may be due to Copper being diamagnetic in nature.

Referring to Fig. 10, it can be observed that in $4 \mathrm{~mm}$ thick disc, the time taken for speed reductions are $1.19 \mathrm{~s}, 1.21 \mathrm{~s}, 1.6 \mathrm{~s}$ and $1.63 \mathrm{~s}$ at $2000 \mathrm{rpm}, 3000 \mathrm{rpm}, 4000 \mathrm{rpm}$ and 5000 
rpm respectively. The time taken is less compared to the time taken in $6 \mathrm{~mm}$ and $8 \mathrm{~mm}$ thick discs. This may be due to better interaction between the properties of Copper and induced magnetization.

Referring to Fig. 11, it can be observed that the decelerations in $4 \mathrm{~mm}$ thick disc are $1.79 \mathrm{~ms}^{-2}, 2.28 \mathrm{~ms}^{-2}, 2.53 \mathrm{~ms}^{-2}$ and $3.12 \mathrm{~ms}^{-2}$ at $2000 \mathrm{rpm}, 3000 \mathrm{rpm}, 4000 \mathrm{rpm}$ and 5000 rpm respectively. The deceleration values of $4 \mathrm{~mm}$ thick disc are higher compared to the decelerations of $6 \mathrm{~mm}$ and $8 \mathrm{~mm}$ thick discs. From experimental investigations it was found that very high repulsion was experienced by $8 \mathrm{~mm}$ thick discs at $4000 \mathrm{rpm}$ and $5000 \mathrm{rpm}$. The magnet could not travel close to the rotating disc because of high repulsion.

From the experimental investigations it was observed that the brake parameters were better in $4 \mathrm{~mm}$ thick disc compared to $6 \mathrm{~mm}$ and $8 \mathrm{~mm}$ thick discs. As very high repulsion was experienced by $8 \mathrm{~mm}$ thick disc, $8 \mathrm{~mm}$ thick disc may not be suitable for both high speed trains and high speed automotive applications. Because of higher $\%$ of speed reduction, higher deceleration and less time taken for speed reduction, $4 \mathrm{~mm}$ thick disc may be more suitable for high speed automotive applications in single magnet with sudden application condition.

\section{Conclusions}

From the experimental investigations it is found that in single magnet condition with $4 \mathrm{~mm}$ thick disc, higher speed reduction, time taken is less and higher deceleration are achieved compared to that in 2 coaxial magnets condition. Hence, $4 \mathrm{~mm}$ thick disc in single magnet condition may be more suitable for high speed train applications.

From the experimental investigations in single magnet with sudden application condition, it is found that deceleration in $4 \mathrm{~mm}$ thick disc is higher and time taken is lesser compared to that in $6 \mathrm{~mm}$ and $8 \mathrm{~mm}$ thick discs. Because of higher \% of speed reduction, higher decelerations and less time taken for speed reduction, $4 \mathrm{~mm}$ thick disc may be more suitable for high speed automotive applications. Single magnet with sudden application condition may also be used as braking system for high speed cars as there is a necessity of speed reduction only and not stopping. Since it is a contactless braking, the problems of temperature rise and loss of friction coefficient may be greatly eliminated.

\section{References}

1. Kung SW, Dunlop KB, Ballinger RS. "Complex Eigenvalue analysis for reducing low frequency brake squeal". Technical report 2000 - 01 - 0444, Warrendale (PA); SAE (2000)

2. Dunlop KB, Richle MA, Longhouse RE. "An investigative overview of automotive disc brake noise", SAE paper (1999).

3. Mario Triches Junior, Samir N.Y.Gerges, Roberto Jordan, "Analysis of brake squeal noise using the finite element method: A parametric study". Applied Acoustics Vol.69, pp.147-162(2008)

4. Andreas Wagner, Gottfried Spelsberg - Korspeter, Peter Hagedorn, "Structural optimisation of an asymmetric automotive brake disc with cooling channels to avoid squeal", Journal of Sound and Vibration, pp.1 - 11,(2013)

5. R. Sedaghati, "Benchmark case studies in structural design optimisation using the force method", International journal of solids and structures Issue 42, pp.5848 $5871,(2005)$ 
6. Y. D. Kwon, S. B. Kwon, S. B. Jin, J. Y. Kim. "Convergence enhanced genetic algorithm with successive zooming method for solving continuous optimisation problems". Computers and structures Issue 81,pp.1715 - 1725,(2003)

7. N. Ali, K. Behdinan, Z. Fawaz. "Applicability and viability of a GA based finite element analysis architecture for structural design optimisation". Computers and structures Issue 81, pp.2259 - 2271,(2003)

8. Sherif H. "Investigation on effect of surface topography of pad / disc assembly on squeal generation". Wear, Issue 257 (7 - 8), (2004), pp.687 - 695

9. H. Hetzler, K.Willner, "On the influence of contact tribology on brake squeal", Tribology International, Vol.11, pp.237 - 246, (2011)

10. A. Akay, O. Giannini, F. Massi, A. Sestieri, "Disc brake squeal characterization through simplified test rigs", Mechanical systems and signal processing, Vol.16, pp. 2590 - 2607, (2009)

11. AliBelhocine, MostefaBouchetara, "Thermomechanicalmodelling of dry contacts in automotive disc brake", International journal of Thermal Sciences Vol.60, pp.161 170, (2012)

12. Thomas J. Mackin et al, "Thermal cracking in disc brakes", Engineering Failure Analysis, Issue 9, pp.63-76, (2002)

13. H. S. Qi, A. J. Day, "Investigation of disc / pad interface temperatures in friction braking”, Wear Issue 262, pp.505 - 513, (2007)

14. H. S. Qi, A. J. Day, K. H. Kuan, G. Rosala. A contribution towards understanding brake interface temperatures". In: proceedings of the international conference 'braking 2004 - vehicle braking and chassis control; Leeds, UK, 7 - 9 July, (2004)

15. T. Valvano, K. Lee. "An analytical method to predict thermal distortion of a brake rotor". Society of Automotive Engineers, Inc, 2000 - 01 - 0445,(2000)

16. P. J. Blau, J. C. Mclaughlin, Tribol. Int 36,pp.709 - 715,(2003)

17. J. Bijwe, Nidhi, N. Majumdar, B. K. Satapathy, "Influence of modified phenolic resins on the fade and recovery of friction materials", Wear, Issue 259, pp.1068 - 1078, (2005)

18. H. Smales, "Friction materials - black art or Science?"J.Automob.Eng.Issue 209, pp.151 - 157,(1995)

19. Mukesh Kumar, Jayashree Bijwe, "Studies on reduced scale tribometer to investigate the effects of metal additives on friction coefficient - temperature sensitivity in brake materials", Wear, Vol.269, pp.838 - 846, (2010),

20. "Brake lining quality control procedure", SAE J661a, in: SAE Handbook, SAE, Detroit, MI, pp.31 - 55, (1978)

21. "Replacement brake lining assemblies", E.C.E Regulation no. - 90 INTEREUROPE Regulation ltd, UN, (1993)

22. U. S. Hong, S. L. Jung, K. H. Cho, M. H. Cho, S. J. Kim, H. Jang. "Wear mechanism of multipurpose friction materials with different phenolic resin matrices", Wear, Issue 266 (7 - 8), pp.739-774, (2009)

23. RukiyeErtan, NurettinYavuz, "An experimental study on the effects of manufacturing parameters on the tribological properties of brake lining materials", Wear, Issue 268, pp.1524 - 1532, (2010)

24. Osman TahaSen, Jason T. Dreyer, Rajendra Singh, "Low frequency dynamics of a translating friction element in the presence of frictional guides, as motivated by a brake 
vibration problem", Journal of Sound and Vibration, Issue 332, pp.5766 - 5788. (2013)

25. S. Lignon, J-J. Sinou, L. Jezequel, "Stability analysis and $\mu$ - synthesis control of brake systems", Journal of Sound and Vibration, Issue 298, pp.1073 - 1087, (2006)

26. Der - Ming Ma, Jaw - KuenShiau: The design of Eddy current magnet brakes. Transactions of the Canadian Society for Mechanical Engineering”, Vol.35, No.1, (2011).

27. Marc T. Thompson: Practical Issues in the use of NdFeB Permanent Magnets in Maglev, Motors, Bearings and Eddy Current Brakes, Proceedings of IEEE, Vol.97, Issue 11, pp.1758 - 1767, (2009)

28. Schykowski, Jennifer: Eddy - current Braking: A long road to success. Railway Gazette, DVV media UK Ltd.(2013) 